\title{
Motivating hospital personnel for excellence in a rough environment
}

\author{
Narcis COPCA \\ "St. Maria" Clinical Hospital and The Bucharest University of Economic Studies, Bucharest, \\ Romania
}

Constanta MIHAESCU-PINTIA

National School of Public Health, Management and Professional Development Bucharest, Bucharest, Romania

cipivil@yahoo.com

\begin{abstract}
Work motivation and satisfaction are core performance factors, of a broad complexity in healthcare. In spite of all economic, political, administrative, regulatory or bureaucratic adversities, there are public Romanian hospitals striving to perform at European level. Medical personnel dissatisfaction, and shortage due to migration are significant challenges for managers. Methodology: the main research question is whether motivation is a key factor in a public Romanian hospital oriented to clinical excellence, reflected by retention of medical staff and their professional satisfaction, and also perceived by their patients. Purpose: to analyze importance and level of job satisfaction of hospital personnel in relation with other motivation components given the rough environment of Romanian public healthcare system, and its reflection on patient satisfaction. The paper is based on two studies: professional satisfaction survey conducted among all 350 employees of the Clinical Hospital "St. Maria" Bucharest accredited for liver transplantation and achieving great clinical performance, based on a 21-questions semi-structured questionnaire. Second, a patient satisfaction survey conducted on a sample of 75 patients randomly selected from all 5 hospital departments, out of an average of approximately 230 patients per week, by applying on discharge day a questionnaire of 30 questions. Results: Great majority of our personnel appreciated as appropriate: their working conditions, communication and relationship with hierarchic boss and with hospital management team. 84.6\% of medical and $90.5 \%$ of nonmedical personnel declared to be professionally very satisfied and satisfied in this hospital. Patient satisfaction analysis indicated that almost all respondents were informed by medical personnel about their conditions and rights, receiving explanations about treatment; $90 \%$ considered care received at a very good quality, except for food; $90.2 \%$ of respondents rated as very good the personnel kindness, availability, communication, information and care; 67,2\% of patients stated as very satisfied and $23 \%$ satisfied with the medical care received, and all respondents would choose this hospital again if needed and even would recommend it to others. Conclusion: Anticipating their needs and motivating hospital personnel to achieve high performance is of great importance for managers and employees, by focusing on people and using appropriate tools even when no direct financial incentives are possible. Professional satisfaction has to be periodically measured, correlated with patient surveys and followed by specific actions for improvement and kept high, thus allowing climbing up to the best hospitals in Bucharest, despite significant challenges within Romanian public healthcare system. Our analysis showed the importance of job motivation and satisfaction in public hospitals, despite the rough environment, and reflection of work satisfaction on employees-patients relationship in terms of availability, communication, providing information and feedback, care, and choice/preference for future services. Thus, our research objectives were fulfilled.
\end{abstract}

Keywords: motivation, professional satisfaction, hospital performance, patient satisfaction, Romania. 


\section{Introduction}

As personnel accounts for the most critical resource of healthcare industry, their work motivation and satisfaction are a core condition for fulfilling the mission and expected performance in health organizations, especially hospitals. Complex and liberal par excellence, medical profession is characterized by: long term exigent training, high specialization, very distinct organizational culture, high clinical risk, appropriate technology use, practice variations, "high-caste" behavior, adaptation to healthcare system, implying costs, payments and rules accordingly.

International ranking positioned Romania on 52nd for human development out of 155 countries (UNDP, HDI, 2015), 56 ${ }^{\text {th }}$ (out of 189 countries) for GDP per capita of only \$PPP 21,403 compared to EU average of \$PPP 35,604.78 in 2015 (IMF, 2017), and 62nd for competitiveness (Schwab et al, WEF, 2016). Romanian healthcare system, based on social health insurance, ranked on just $32^{\text {nd }}$ position (getting only 527 points) among the 35 countries assessed by the European Health Consumer Index (Bjornberg, 2016). Here medical professionals are subject of a significant migration mostly since 2007 - integration in EU. Main reasons are low salaries, poor working conditions and limited career advance (Vladescu et al, 2016). Main indicators related to this healthcare system in comparison with EU averages are presented below, describing a former Semashko, poor financed sector affected by corruption, ineffective management, lack of adequate reforms, bureaucracy and low quality standards.

Table 1. Bench indicators of Romanian healthcare system compared with EU averages, 2014

\begin{tabular}{|l|l|l|}
\hline Indicator & Romania & EU \\
\hline Life expectancy at birth (years) & 75.72 & 80.87 \\
\hline Infant deaths per 1000 live births & 8.35 & 3.69 \\
\hline $\begin{array}{l}\text { Standardized death rate all causes, all ages, } \\
\text { per 100,000 inhabitants }\end{array}$ & 828.75 & 559.85 \\
\hline Total health expenditure as \% of GDP & $5.57 \%$ & $9.45 \%$ \\
\hline Total health expenditure, PPP per capita & 1079.26 & 3508.77 \\
\hline Physicians per 100,000 & 276 & 349.58 \\
\hline \% physicians working in hospitals & 49.75 & 56.75 \\
\hline Nurses per 100,000 & 581 & 864.29 \\
\hline Hospitals (public and private) per 100,000 & 2.65 & 2.91 \\
\hline Hospital beds per 100,000 & 660 & 521,62 \\
\hline Inpatient care discharges per 100 & 20.69 & 17.34 \\
\hline Average length of stay in hospitals (days) & 7.53 & 8.16 \\
\hline Outpatient contacts / person / year & 4.8 & 7.03 \\
\hline
\end{tabular}

Sources: WHO, Health for all database, http://data.euro.who.int/hfadb/; NIS, 2016.

Health and resource utilization indicators reflect a population relying on hospital care in absence of appropriate preventive and primary care, resulting in a relatively poor health status especially for certain groups, and avoidable morbidity and mortality. Within this healthcare system, management is a continuous challenge especially in hospitals, while job motivation and satisfaction are even more difficult to achieve, given the reasons mentioned above.

\section{Literature review}

\section{Work motivation and satisfaction}

Motivating people means knowing what needs and forces drive them to behave in such ways for getting certain results and/or attaining a certain goal, within a complex process, in 
a given background. Financial and nonfinancial motivation at work has currently gained many forms in different organizations and fields. Armstrong (2009), Pritchard and Ashwood (2008), Robbins and Judge (2013) and other authors seem to agree on three main elements to define motivation: direction, effort and persistence.

In Armstrong view, leading motivation theories and concepts are the following:

- Taylor instrumentality - using positive and negative incentives as motivators;

- Hull reinforcement theory - based on feedback to reinforce desired behavior;

- needs / content theories - motivating people by satisfying their different needs;

- process / cognitive theories - expecting rewards after effort; following an agreed goal and receiving feedback; equitable treatment and reward; social learning.

- Herzberg two-factor model: job satisfaction based on intrinsic factors to work itself and extrinsic motivators (payment and working conditions);

- McGregor theory X and $\mathrm{Y}$ - coercion versus commitment and self-direction, integrating individual and organizational needs (Armstrong, 2009).

Griffin and Moorhead found that, for job performance, motivation is a core condition very difficult to manage, along with ability and environmental factors. According to human resource approach to motivation, people naturally like to participate, work and make meaningful contributions, determining many of contemporary employers to better organize work environment and value their human capital, also considering needs as employees and individuals. Authors also mentioned complexity of motivation structure, as in Herzberg theory: motivation factors affecting satisfaction - fulfillment, recognition, work activity per se, accountability, promotion, growth, and also "hygiene factors" of dissatisfaction supervision, working conditions, relationships, payment and job stability, organization policies (Griffin and Moorhead, 2014).

Robbins and Judge emphasized importance of appropriate job design, positively influencing job satisfaction and thus performance, and of adequate rewards for increasing motivation and satisfaction at work. According to Job Characteristics Model developed by Hackman and Oldham, for getting expected results and high satisfaction with work, job design should consider the features and combination of: skill range and abilities, task identity, task significance, autonomy and feedback. Hereby job redesign could succeed by actions such as recognition, rotation, diversified enrichment, participative management and different flexible work arrangements (job sharing, telecommuting etc.). Financial rewards should envisage both individual and organizational performance, and use applicable bonuses, benefits, merits, certain incentives (Robbins and Judge, 2013).

According to Pritchard and Ashwood, job motivation and satisfaction are fundamental, logical and collaborative, so it has to be well understood and considered by managers, as long as it is all about behavior and a win-win relationship: by improving motivation of their people, organization gets better performance while individuals better satisfy their needs, including satisfaction of doing a good job. Motivation is seen by these authors as the process to allocate effort to maximize the satisfaction of needs (organizational and individual), based on five connected components: actions, results, evaluations, outcomes, satisfaction. Therefore, improving motivation requires capability, anticipation, adequate resources (information, technology, money, time, supplies, tools etc.) available, right authority / autonomy, appropriate work strategies and measurement (Pritchard and Ashwood, 2008). 
Motivating medical professionals is also a matter of health system and country specific, with significant socio-cultural differences. Motivating hospital staff is a premise for avoiding turnover and shortage, delivering good quality services, getting patients satisfied and improving outcomes, performance and image of organization - all advantages on a quite competitive market, because "patient follows the doctor".

For academic hospitals, Gunderman assumes that certain measures allow motivation and effective leadership: encourage interdisciplinary collaboration, stimulate teaching and research concomitant with healthcare delivery taking full advantage of specialization, knowledge sharing as a way to attain excellence, contribute to personnel self-actualization including by key leadership skills (such as communication, planning, financial management), allow participation in decisions, turn to modern adaptable organization instead of paternalist, traditionalist (Gunderman, 2009).

Good hospital managers anticipate the main needs of their personnel and motivate them accordingly. Financial and nonfinancial rewards have to meet people needs, otherwise their motivation is not enhanced. On the other hand, patient satisfaction is a result influenced by staff motivation, that has to be periodically measured. Work satisfaction and motivation are reflected on relationships between hospital employees and their patients, in terms of: dedicated time and attention, communication, collaboration, compliance to treatment, feedback, respect, politeness, kindness, follow-ups.

Getting people motivated in public Romanian hospitals is currently very difficult, rather an individual choice for managers, empirically done by some, than a usual practice based on specific methods, data and good practice. Jobs in public hospitals have been blocked for years, and salaries cut off by $25 \%$ in 2010-2013! While many physicians and nurses left public hospitals, causing significant shortages, the other categories of staff remained, resulting an unbalance between medical and nonmedical. Most of hospital doctors use to work both on public and private system, practicing cream-skimming of cases. Moreover, National Social Health Insurance Fund penalizes hospitals if their medical employment scheme is not covered. Managers should also be careful when hiring because it is difficult to fire an employee working in any public sector, even for reasonable motives. There is no national programme for stopping migration of Romanian doctors and nurses, first document considering health personnel a strategic resource and proposing measures was a ministerial proposal for modifying National Health Strategy 2014-2020, published by the Ministry of Health in November 2016 for public consultations (MoH, 2016). Annual evaluation of personnel in public hospitals is just a formal process, not related to work objectives, nor to specific performance, having no effects (promotion, rewards, training, rotation, warning etc.). National Authority for Health Quality Management in Health, in charge with hospital accreditation, only asks for formal documents, not interested in hospital infrastructure, equipment, working conditions, coverage with medical personnel, work satisfaction. Public hospital sector is also under the magnifying glass of a criticizing media campaign for years. Therefore, preoccupation for studying motivation in Romanian public hospitals, is low.

As Romanian legislation forces public hospitals to pay low fixed salaries, financial motivation is limited to academic education and research projects. During last years, management of Clinical Hospital St. Maria applied mainly nonfinancial motivational tools for our staff treating them as a team: significantly improve environment and equipment (from local funds), facilitate continuous education and specialization - including abroad (in 
Hannover Medical School and H.A.B. Hospital, Dept. of Transplantation Surgery), enhance knowledge sharing and collaboration, implement several research projects, asking for and offering feedback, inviting most competent personnel to participate in decision making, open communication, value each person and recognize merits, continuous organizational development - up to achieving top performance services such as complex surgery and liver transplantation. All performance indicators of the hospital in 2016 were at very good levels of achievement, as compared to previous own values, and also with pairs nationally.

\section{Methodology}

Main research question: whether job motivation is a key factor in a public Romanian hospital oriented to clinical excellence, reflected by retention of medical staff and their professional satisfaction, and by patient satisfaction with services received, within a rough environment and a quite competitive market with increasing expectations from healthcare providers.

A professional satisfaction survey was conducted in Clinical Hospital "St. Maria" Bucharest of 290 beds, accredited for liver transplantation and achieving great clinical performance, based on a semi-structured questionnaire of 21 topics, applied through Human Resources department, to all 350 employees, except for the resident physicians and specialists working only in few night shifts. Questions covered the following aspects: working conditions, level of endowment including medical equipment, level of cleanness and development of communal spaces (vestiary, showers, resting room, cafeteria, conference room etc.), number and quality of courses/ training programmes/ events for professional development respondents participated in during last year, communication with hierarchical boss and hospital management, collaboration with other hospital departments, wards and services, safety measures, proposals made for improving their activity and consideration from hospital management for those proposals, extent of using their skills and abilities in current activities, support in their work, hospital policy for personnel development and promotion, overall level of professional satisfaction in this hospital and suggestions for improving the working conditions and relationships. Work satisfaction was measured after a series of improvements in working conditions, clinical activity and management.

This study was followed by a patient satisfaction survey (semi-structured questionnaire of 30 questions), applied to a sample of 75 patients of different clinical complexity randomly selected from all five hospital departments (15 per each), out of approx. 230 patients discharged per week in total. Questions referred to: hospital admission type, status and details; patient rights and responsibilities during the stay (current episode); medical tests, investigations and treatments received during their stay, including surgery; quality assessment in terms of cleanness, linen, toilet and shower, diet and food receiving, availability and gentleness of medical personnel, communication with hospital staff, general and medical information received (about health problems, investigations, treatments), care received during the stay; waiting times for different services in hospital; level of satisfaction towards medical care received during the stay; overall quality of services received during the stay; choosing this hospital again, recommending it to other patients; observation and suggestions. Aspects studied are direct related to the main components of hospital care, pathways but also certain features usually critiqued, condemned in Romanian public hospitals during last decades (such as tidiness, 
waiting times, relationship with the personnel, buying medicines/materials/devices during the stay).

Three- and five-level Likert scales were used for rating responses on both questionnaires. Period of applying both questionnaires: second week of April 2016.Both questionnaires were collected in dedicated boxes, located at HR Department - for personnel, and in each hospital department - for patients, respecting confidentiality and the other rights. Neutral, nonmedical researcher coded and analyzed the data.

\section{Results}

\section{Personnel survey}

Questionnaire was applied to all 350 employees, getting a good response rate of $94.9 \%$ (332 persons), out of whom 290 (87.35\%) are medical personnel from all medical/surgical departments and services, while the rest of 42 are nonmedical staff. 18 respondents (5.4\%) are in a managerial position (clinical department head, chief nurse, administration). As expected in healthcare, women are predominant: $59.5 \%$ of total respondents and even $82.8 \%$ on medical departments. Age distribution is: $8.1 \% \leq 30$ years old, majority of $48.8 \%$ (162 employees) being 31-45 years old, and the rest of $43.1 \%$ within the age group $46-65$ years.

Not specific for public hospitals in Romania, medical staff represents here an important share of total employees (66\%), also of respondents (87\%!), as a result of hospital HR policy (attract and retain good medical professionals up to optimum coverage and externalizing nonmedical services - catering, ancillary etc.). Being highly motivated and not overload (1227 outpatient consultations and 270 discharges in average per doctor), despite the complexity of cases treated, no physician or nurse migrated from this hospital during last years, despite the national accentuated trend. In terms of clinical excellence, our general surgery team achieved 40 successful liver transplants and hundreds of top performance, complex surgical procedures in our patients during last three years, while our rheumatology team was the best specialty service at national level. Recently our hospital acquired the accreditation for lung transplantation, a national premiere, as a step within a more extended effort to develop a multi-organ transplantation center, the first one in Romania and of importance in South-Eastern Europe, a project well supported by local authorities.

Overall, professional satisfaction freely expressed by our staff in this survey range high, generally indicating good working conditions, relationships, motivation and certain preoccupation for their activities and performance.

In terms of participation in training, courses, internships or different continuous education and professional development programs, majority of medical professionals attended at least one, while $49(16.9 \%)$ medical plus 30 nonmedical staff did not attend any training. Details in figure 1 below. 18 persons (5.4\% of respondents) declared no participation in short training on professional risks last year. Situation of personnel with no training at all should be further analyzed and improved. 


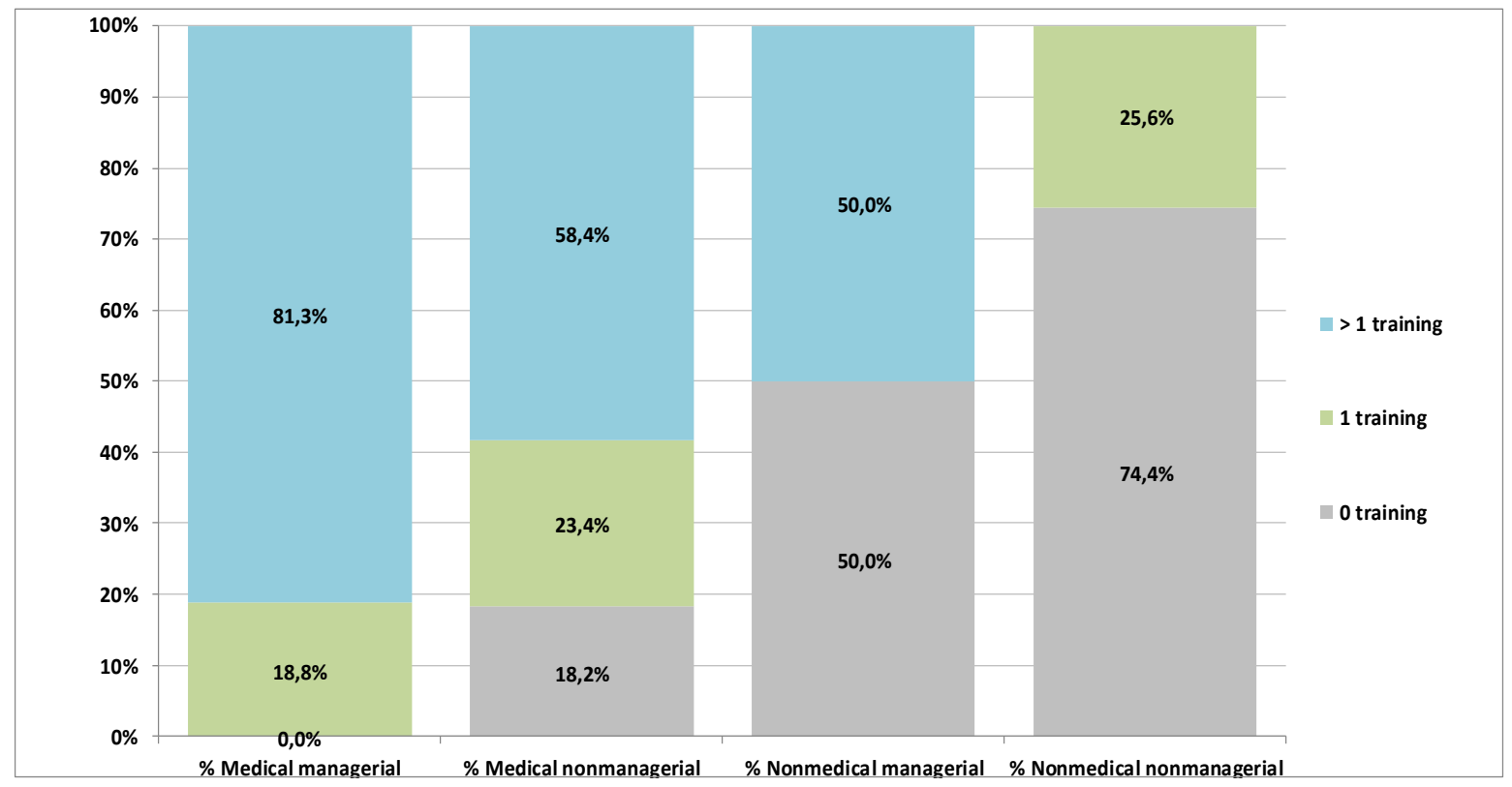

PICBE | 374

Figure 1. Level of participation in training for professional development, per categories

Source: Authors' own research.

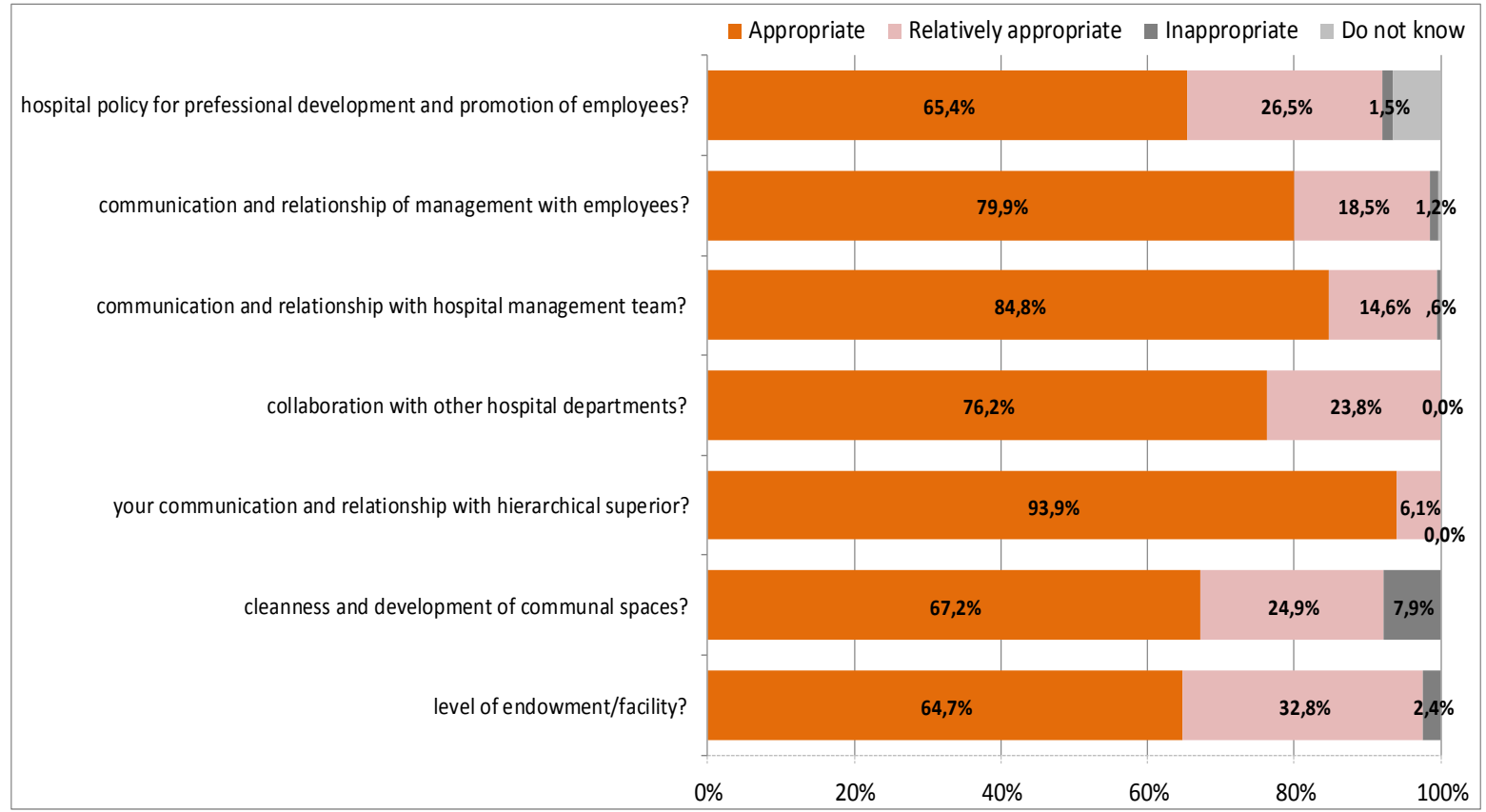

Figure 2. Opinion on appropriateness of different organizational aspects of work

Source: Authors' own research.

Figure 2 from above presents several work satisfaction aspects measured. Working conditions in the hospital were found appropriate by $67.8 \%$ respondents and quite appropriate by other $31 \%$ of them. But $7.9 \%$ of respondents found inappropriate the cleanness and development of communal spaces, while $2.4 \%$ marked the endowment as inappropriate, aspects to be further investigated and improved. 312 respondents (94\% of total) thought that communication and relationship with hierarchic boss are all right, while $85 \%$ of respondents consider appropriate the communication and relationship with hospital management team, as availability and openness are practiced. 
Most of respondents declared they feel supported and encouraged in their activity, only 10 persons (3\%) declared the contrary, and causes should be learned and further necessary actions done in order to remedy this situation without affecting the hospital activity. Attention should also be paid to those respondents (27 representing 8.3\%) who considered they used their professional competence and abilities during daily work only to a certain extent, not entirely, which is a waste for themselves and organization. But $84 \%$ of staff use their professional competence, abilities and aptitudes to the greatest extent in their daily hospital activities.

In terms of participative role in organization, $45 \%$ of respondents (most of them nonmedical staff) did not proposed improvements of their workplace and activity, while the great majority of those who made improvement requests or propositions (178 persons), have seen their requests/recommendations came true as the hospital board did take them into consideration, as seen in Figure 3 below. This might suggest that a simple form for recommendations could be periodically distributed and responses properly analyzed.

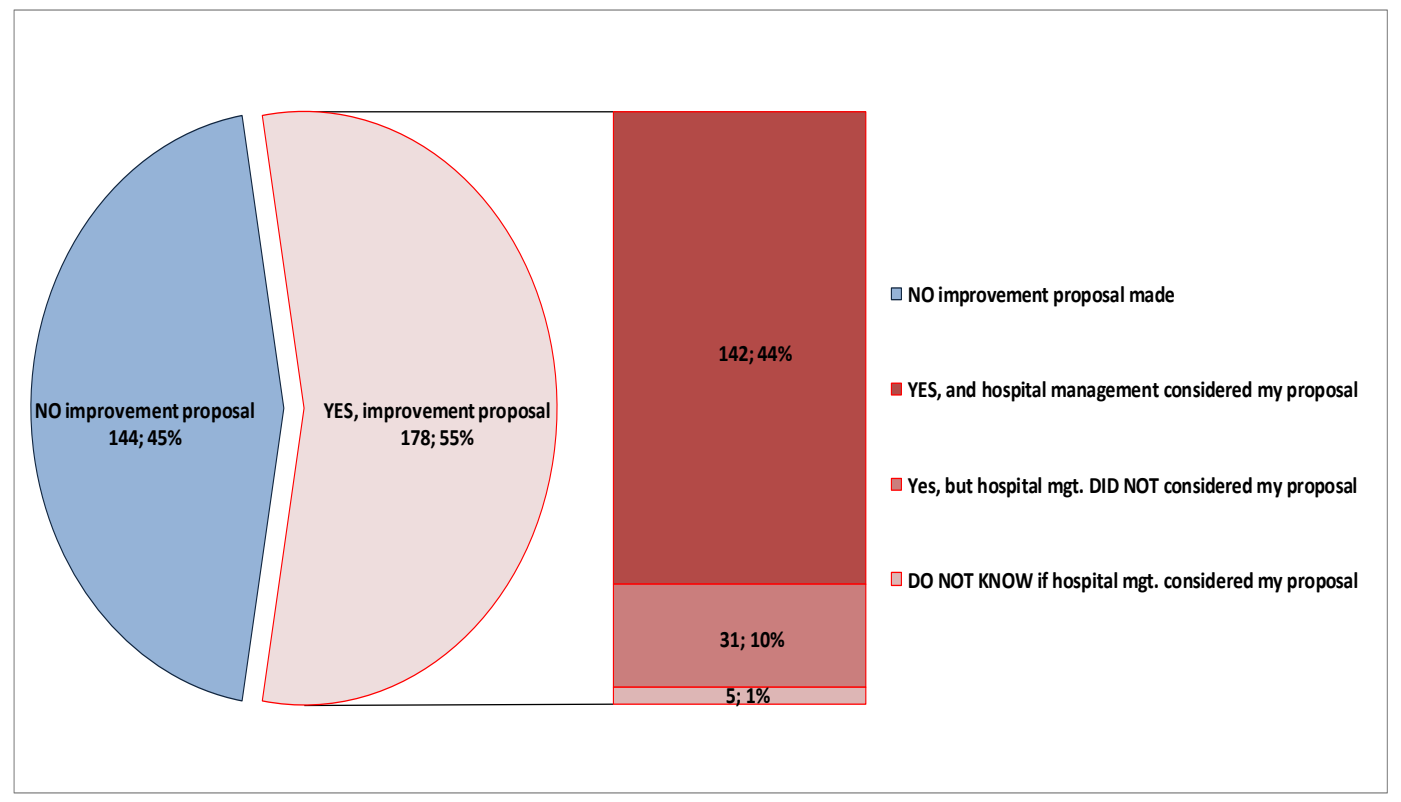

Figure 3. Staff proposals for improvements

Source: Authors' own research.

Overall professional satisfaction seem to be at good level, as resulted from our survey: $84.6 \%$ of medical personnel and $90.5 \%$ of nonmedical personnel (totalizing 279 persons) declared to be very satisfied and satisfied working in this hospital. Differences between medical and nonmedical staff and according to their executive position, are presented in the figures 4 and 5 below. Many of the results observed in this study have also been expressed by the people within their work interactions including with hospital management.

On the other hand, job satisfaction of medical professionals is also perceived by patients in their direct inter-relationships during the stay, as patient survey found. 


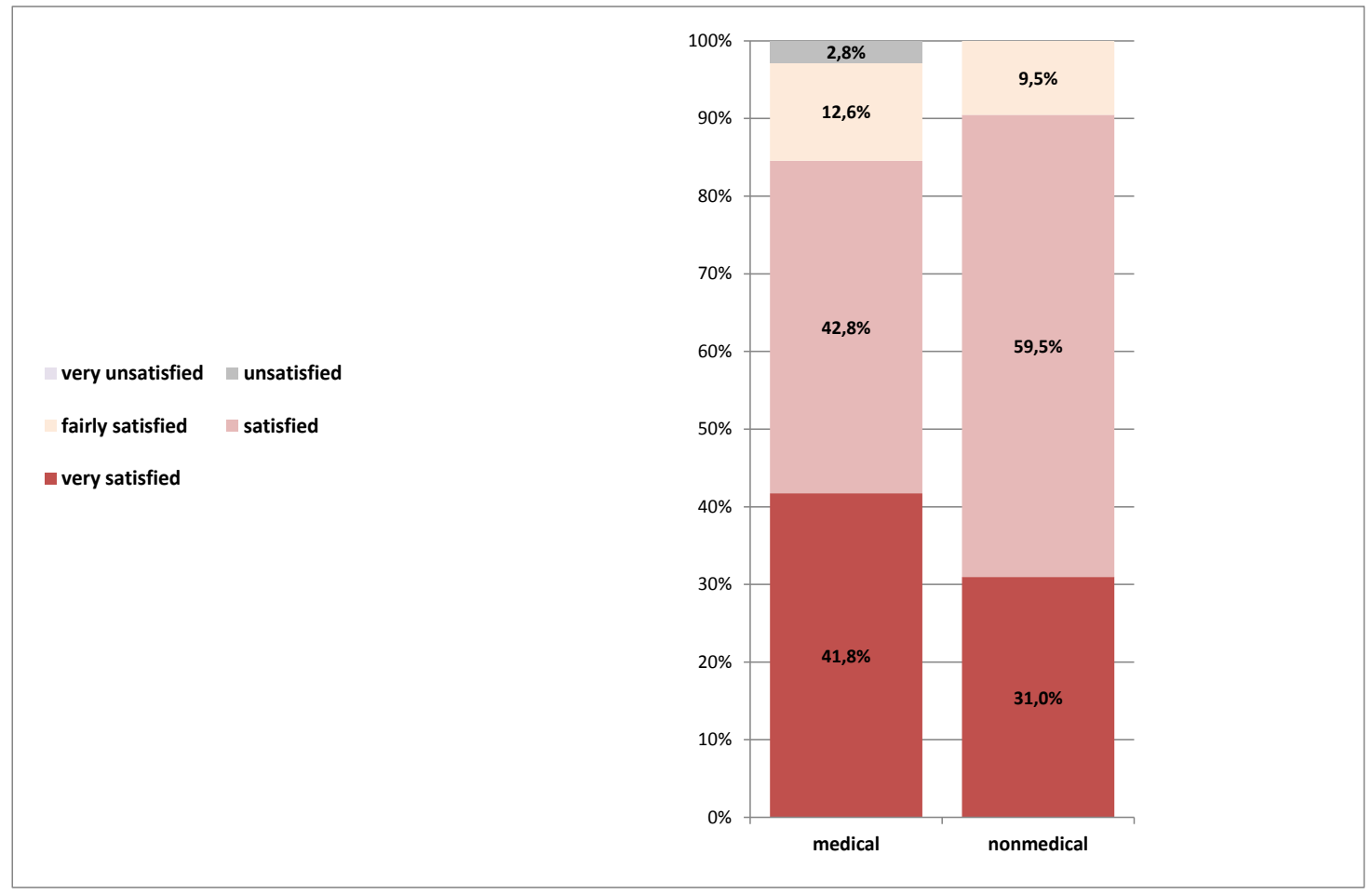

Figure 4. Level of professional satisfaction in the hospital, distributed by medical and nonmedical category of personnel

Source: Authors' own research.

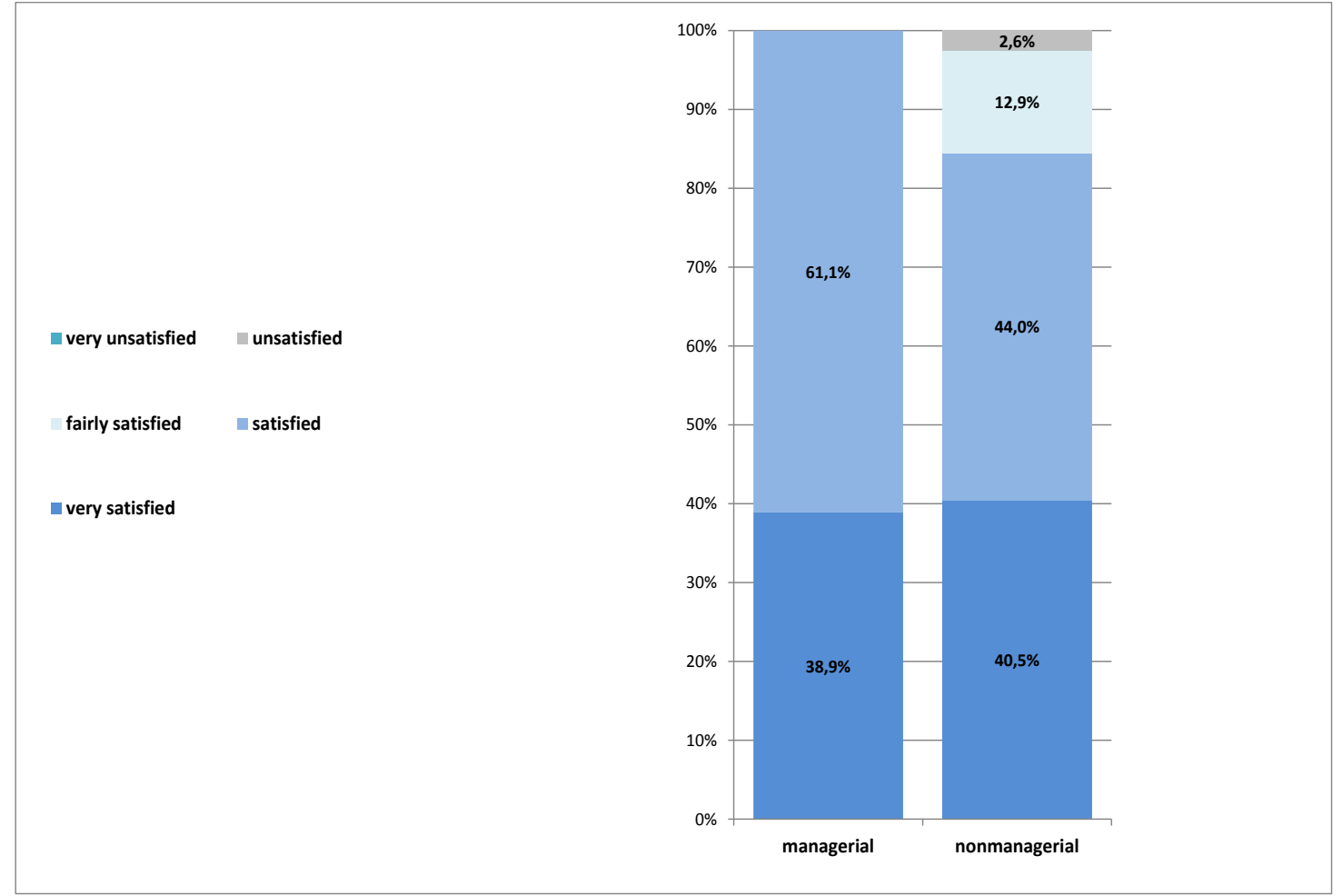

Figure 5. Level of professional satisfaction in the hospital, distributed by executive (management) and nonexecutive position

Source: Authors' own research. 
11.1\% respondents (both satisfied and unsatisfied) have written interesting suggestions and practical proposals for organizational improvement, being discussed by the hospital board. Reasons and causes of professional dissatisfaction discovered in this survey are to be further investigated and corrections made accordingly, as possible.

\section{Patient survey}

PICBE | 377

Unlike personnel survey, not frequently practiced in public hospitals, patient satisfaction studies started to become a practice but not followed by consequent decisions for improvements.

75 questionnaires have been randomly distributed to patients of all the five hospital wards (15 per each), on the last hospital day before discharge; 61 questionnaires filled out have been collected from the special boxes during month April, meaning a response rate of 81.3\%; later responses have not been considered in this study. Hospital personnel did not interfered with their patients during their filling out, and questionnaires have been collected by a researcher not involved in patient care. Most of respondent patients (85.2\%) have been admitted in hospital by medical referral, while only $14.8 \%$ were emergencies. Their distribution on hospital wards: 10 patients from Internal medicine department plus one from its Cardiology compartment, 15 from Rheumatology, 15 from General surgery I, 13 from ENT and 7 patients from General surgery II (ward of the most severe and complex cases, including hepatic transplantation).

Age distribution of respondents indicated that most of the patients were over 45 years old (42 representing almost 70\%) and only 7 patients were young of 18-30 years old:

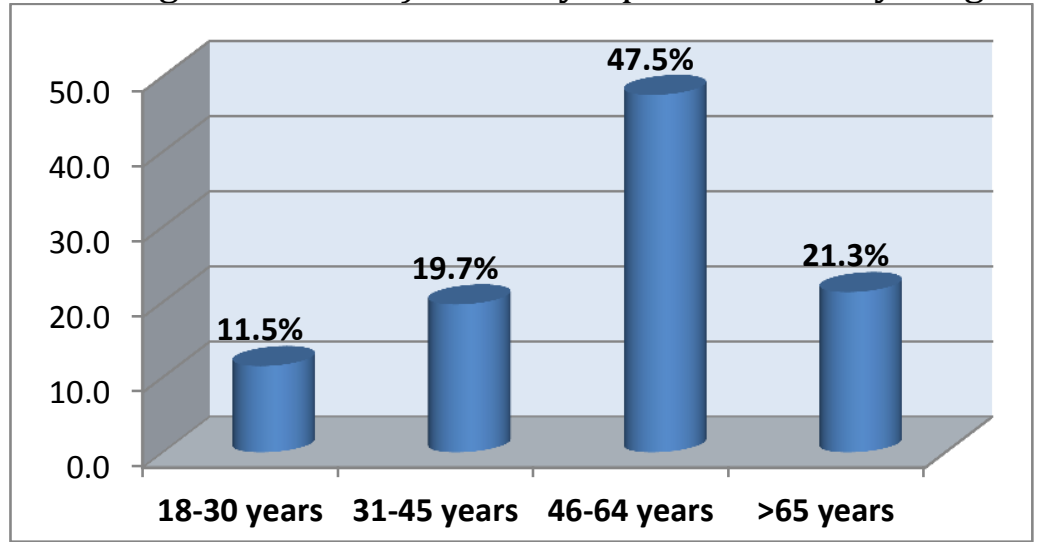

Figure 6. Age distribution of responding patients

Source: Authors' own research.

Gender distribution of this group of patients was quite balanced, 57.4\% women $42.6 \%$ men, while the majority (75.4\%) of them were urban and only $24.6 \%$ rural population. From educational point of view, 39.3\% respondents declared university studies and $44.3 \%$ had secondary education (apparently surprising but corresponding to Bucharest profile, as most of St.Maria Clinical Hospital patients originate), while only $16.4 \%$ of respondents - primary education.

Once admitted, only $23 \%$ of patients have been accompanied to their wards by hospital staff and $36.1 \%$ - by a relative.

Analysis of their answers indicated that: $98.4 \%$ of respondents have been informed by the medical personnel about patient rights and about their medical problems causing current hospital admittance; 95\% received explanations about the treatment prescribed in 
hospital, while only one patient declared the contrary; $80.3 \%$ patients did not buy any medication or health materials during the stay an three patients did not answer; $90 \%$ considered the hospital care received at a very good quality, while food was not very good appreciated; $90.2 \%$ of respondents rated as very good the personnel kindness, availability, communication, information and care; $67.2 \%$ of patients stated as very satisfied and $23 \%$ satisfied with the medical care received and all the respondents said they would choose this hospital again if needed and even recommend it to others.

Table 2. Quality of nonmedical components of care in patient perception

\begin{tabular}{|l|c|c|c|}
\hline \multirow{2}{*}{ Aspect assessed } & \multicolumn{3}{|c|}{ Quality level } \\
\cline { 2 - 4 } & very good & average & poor \\
\hline a) Cleanness & $\mathbf{4 8}$ & 11 & 0 \\
\hline b) Linen & $\mathbf{5 0}$ & 9 & 0 \\
\hline c) Bathroom (toilet and shower) & $\mathbf{3 6}$ & 20 & 3 \\
\hline d) Dining conditions & $\mathbf{4 9}$ & 9 & 0 \\
\hline e) Food received & $\mathbf{3 6}$ & 18 & 3 \\
\hline f) Availability and kindness of medical personnel & $\mathbf{5 5}$ & 3 & 0 \\
\hline g) Communication with personnel & $\mathbf{5 5}$ & 4 & 0 \\
\hline h) Information received & $\mathbf{5 5}$ & 4 & 0 \\
\hline i) Care received during the stay & $\mathbf{5 5}$ & 3 & 0 \\
\hline
\end{tabular}

Source: Authors' own research.

$59 \%$ respondents appreciated as very good the quality of all nonmedical aspects assessed and 18 patients (29.5\%) rated food as of average quality, while some patients did not filled out all question items. But patients wrote their complaints as final suggestions and personnel checked out to remedy. Very important is the fact that $90.2 \%$ respondents rated at very good quality the availability, kindness, communication, information and care received, reflecting work motivation and satisfaction of our personnel, and anyone might test these staff attitude features with any of our patients. People use to remark from the beginning of their stay that all our personnel speak polite and are kind and helpful with them, in contrast with many other public health facilities.

Table 3. Level of patient satisfaction regarding medical care received in our hospital

\begin{tabular}{|c|c|c|c|c|c|c|}
\hline Indicator & $\begin{array}{c}\text { very } \\
\text { satisfied }\end{array}$ & satisfied & $\begin{array}{c}\text { quite } \\
\text { satisfied }\end{array}$ & unsatisfied & $\begin{array}{c}\text { very } \\
\text { unsatisfied }\end{array}$ & $\begin{array}{c}\text { Non } \\
\text { response }\end{array}$ \\
\hline No. of patients & 41 & 14 & 3 & 0 & 1 & 2 \\
\hline Percentage & $\mathbf{6 7 . 2 \%}$ & $\mathbf{2 3 \%}$ & $4.9 \%$ & 0 & $1.6 \%$ & $3.3 \%$ \\
\hline
\end{tabular}

Results of this survey did not diverge from others conducted on our patient satisfaction and future studies are to be achieved with improved tools and correlated with professional satisfaction surveys, followed by further investigations and measures aimed to continuously improve the quality of care. More sophisticated statistical analysis is possible but it was not our purpose in these early stages of measuring satisfaction.

\section{Conclusion}

We consider our research objective achieved, as motivation and satisfaction of our hospital personnel proved to be determinant for high performance also reflected in patient perception, although a process difficult to anticipate and manage. Nonfinancial motivations and innovation showed a particular importance especially for public Romania hospitals, while migration of medical personnel was a significant threat. Certain improvements in hospital environment, medical equipment, participation in research projects, in training, 
supporting and encouraging the personnel in their work, knowledge sharing and daily communication, participation in decisions, organizational development, approaching and performing top services and other measures, are elements proved to increase work motivation and satisfaction. Professional satisfaction in public hospitals has to be periodically measured within a constructive, confidential process, followed by actions aimed to maintain a highly motivated team, despite usual formality and inefficiency of public sector. Tools used to assess satisfaction of personnel and patients have to be carefully built and applied without interferences or sanctions, in order to provide management with relevant information about problems, areas of improvement.

Our research and practical experience showed that public management in health may and should be much more people-oriented. Many Romanian medical professionals wish to contribute and perform top services at European level on very complex cases in a great working environment they feel to belong, being respected, understood, valued and involved, sharing same mission and vision. Competent medical personnel should be involved in specialized research and training activities in order to develop their career and compensate low fixed salaries. In this way, quality of hospital services will not remain just a theoretical, complicated concept, compulsory mentioned in formal documents, but become a way of work and be perceived accordingly by patients. Leadership of academic medical centers cannot remain in the past, paternalistic, but become more effective, competitive and innovative, with inspirational individuals representing personal examples for their team and not afraid to use relevant research results as evidence to document decisions. Our surveys prove why is necessary for public hospitals to really study satisfaction of personnel and patients (without faking the process), and act accordingly. And achieving a great premiere in Romania of a multi-organ transplantation center, as an excellence facility of Eastern-European importance, will be next important motivator for our personnel. In parallel, our patients can feel motivated staff in the way they are approached and treated daily. To those complaining of poor financing: we know politeness, respect, consideration and caress - both for patients and employees, do not cost a dime.

\section{References}

Armstrong , M. (2009). A Handbook of Human Resources Management. 11 th edition. Kogane Page, Great Britain. Part IV Organizational behavior, Motivation, pp. 316-332.

Bjornberg, A. (2016). Europe Health Consumer Index 2015 Report. Health Consumer Powerhouse, accessed February 2017, http://www.healthpowerhouse.com/news /euro-health-consumer-index-2015/.

Griffin, R.W., Moorhead, G. (2014). Organizational Behavior: Managing People and Organizations, $11^{\text {th }}$ edition. South-Western, Ohio, USA; chapter 4 Motivation in Organizations, pp.90-108.

Gunderman, R.B. (2009). Leadership in Healthcare. Springer-Verlag London

International Monetary Fund. World Economic Outlook Database October 2016, accessed February 2017, https://www.imf.org/external/pubs/ft/weo/2016/02/weodata

/index.aspx.

Pritchard, R.D., Ashwood, E.L. (2008). Managing Motivation. A Managers's Guide to Diagnosing and Improving Motivation. Routlege, Taylor \& Francis Group, NY, U.S.A.

Robbins, S.P., Judge, T.A. (2013). Organizational Behavior. 15th edition, global, Pearson, Essex, England. Chapter 8 Motivation: from Concepts to Applications. 
National Institute of Statistics. (2015). Romanian Statistical Yearbook, Bucharest 2016, chapter Health, pp. 279-281.

Romanian Ministry of Health. (2016). Ministerial proposal for modification and augmentation of the Government Decree no.1028/2014 regarding National Health Strategy 2014-2020 and Action plan, accessed in February 2017, http://www.ms.ro/2016/11/28/hotarare-de-guvern-pentru-modificarea-sicompletarea-hotararii-guvernului-nr-10282014-privind-aprobarea-strategieinationale-de-sanatate-2014-2020-si-a-planului-de-actiuni-pe-perioada-2014-2020/.

Schwab, K. (editor), Sala-i-Martin, X. (2017). The Global Competitiveness Report 20162017, World Economic Forum. accessed February 2017, http://www3.weforum.org/docs/GCR20162017/05FullReport/TheGlobalCompetitivenessReport2016-2017_FINAL.pdf.

UNDP. (2015). Human Development Report 2015 Overview, accessed February 2017, http://hdr.undp.org/sites/default/files/hdr15_standalone_overview_en.pdf.

Vladescu, C., Scintee, S.G., Olsavszky, V., Hernandes-Quevedo, C., Sagan, A. (2016). Romania: Health system review. Health Systems in Transition, 2016; 18(4):1-170.

World Health Organization. (2017). European Health for all database. Regional Office for Europe, http://data.euro.who.int/hfadb/ , accessed February 2017. 